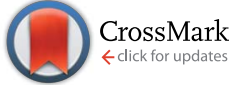

Cite this: RSC Adv., 2016, 6, 76028

Received 25th March 2016 Accepted 30th July 2016

DOI: $10.1039 / c 6 r a 07824 a$

www.rsc.org/advances

\section{A scratch resistant yet healable automotive clearcoat containing hyperbranched polymer and POSS nanostructures}

\begin{abstract}
H. Yari, ${ }^{\star a}$ M. Mohseni ${ }^{\star b}$ and M. Messori ${ }^{c}$
In this paper a typical acrylic melamine clearcoat has been modified with hyperbranched polymer and polyhedral oligomeric silsesquioxane nanostructures to simultaneously enhance its scratch resistance and healing ability. Scratch behaviour and healing performance of clearcoats were investigated by micro-scratching and confocal profilometry techniques. Various techniques were employed to correlate scratch resistance and healing enhancements to the various mechanical and structural characteristics of nano clearcoats. Enhanced scratch resistance was attributed to the increased elastic recovery of the clearcoats in the presence of nano-structured modifiers. In addition, the improved self-healing performance was assigned to the partial replacement of covalent cross-links with physical ones i.e. $\mathrm{H}$-bonding. Simultaneous reinforcement with covalent and physical linkages led to the formation of a more flexible network which maintains its mechanical integrity at ambient temperature and also provides dynamic chain movements for thermal healing treatments at high temperature.
\end{abstract}

\section{Introduction}

Appearance and its retention during service life is an important criterion affecting the overall quality and acceptability of a car body from the customer's view. Weather induced degradation as well as scratches and marring are the most important factors spoiling the automotive coating appearance. ${ }^{\mathbf{1 - 3}}$ Two main strategies can be implemented to eliminate or diminish the influence of scratches; scratch prevention and scratch healing. ${ }^{\mathbf{4 - 1 1}}$ The first includes all strategies which prevent the chance of scratch formation such as increased hardness, slippery surface and toughness-elasticity enhancement of the coating. ${ }^{6,12-15}$ Network reinforcement using increasing crosslinking density or addition of nanoparticles has been the main strategy to enhance the scratch resistance of polymeric coatings. The latter covers all extrinsic and intrinsic mechanisms triggered by external stimuli (like heat, $\mathrm{pH}$, incident rays) that restores the deformed scratched areas to its initial state. ${ }^{\text {9-11,16-20 }}$ Healing of the scratches may be the last opportunity to fight against the effect of scratches. The healing mechanisms comprise encapsulating the healing agents, incorporation of various reversible covalent and non-covalent

${ }^{a}$ Department of Surface Coating and Corrosion, Institute for Color Science and Technology, Tehran, 1668814811, Iran.E-mail: yari-ho@icrc.ac.ir

${ }^{b}$ Department of Polymer Engineering and Color Technology, Amirkabir University of Technology, Tehran, 15875-4413, Iran.E-mail: mmohseni@aut.ac.ir

'Dipartimento di Ingegneria 'Enzo Ferrari', Università di Modena e Reggio Emilia, Modena, 41121, Italy.E-mail: Massimo.messori@unimore.it linkages, introducing various thermoplastic components into the polymeric matrix, etc. ${ }^{11,21-23}$

In general, the scratch preventing and scratch healing strategies are counteractively opposite. While the former focuses on matrix reinforcement, the latter emphasizes on the flexible dynamic networks. Reinforcing the polymeric systems by incorporation of various inorganic nanoparticles have been the subject of many academic attempts in recent decades..$^{2,4,5,24,25}$ Such reinforcements usually restrict the polymeric chains which impede segmental or chain motions needed for further healing, reducing the scratch healing performance. ${ }^{26-29}$ For example, in our recent attempt to enhance the scratch resistance of automotive coatings, hybrid organic/ inorganic silsesquioxane-based nano building blocks were employed. ${ }^{30}$ It was found that while it could significantly promote the scratch resistance via molecular-scale reinforcement, it embrittled the matrix at high loadings, leading to formation of fracture-type scratches which were not healable. $^{30,31}$ On the other hand, various self-healing polymeric systems which have been developed based on healing mechanisms (especially those developed based on fully physical interactions such as $\mathrm{H}$-bonding, ionic interaction) usually suffer from inferior mechanical properties due to lack of chemical cross-linking or chain entanglements. ${ }^{29,32-34}$ Therefore, achieving a scratch resistant polymeric system with excellent healing performance seems challenging. However, it seems that a flexible tough network which can balance the covalent and non-covalent interactions would be promising to achieve a healable scratch resistant system. ${ }^{29}$ 
Controlled physical and chemical linkages in thermosetting systems has been the target of various studies to achieve optimum properties. ${ }^{\mathbf{2 9 , 3 4 , 3 5}}$ Acrylic melamine resin is known as a highly cross-linked network being utilised as a common OEM thermoset automotive clearcoat. Hyperbranched polymers, as novel toughening agents, and polyhedral oligomeric silsesquioxane compounds, as versatile reinforcing agents, have been recently introduced for thermosetting systems. ${ }^{15,24,27,31,36-38}$ Globular scaffold of these two highly branched structures provides them a basic capability to more efficiently interact physically and chemically with the matrix at which they are incorporated..$^{39,40}$ In our previous attempts we have separately incorporated hyperbranched polymers and polyhedral oligomeric silsesquioxane compounds to enhance the toughness and scratch resistance of typical automotive coatings, respectively. ${ }^{15,30}$ It was revealed that low loading of a hyperbranched polyester-amide was sufficient to significantly toughen the thermosetting acrylic melamine system. It was also demonstrated that such improvement was obtained without sacrificing mechanical properties, contrary to most toughening agents. ${ }^{15}$ All properties required for such an application were achievable as a result of compact polar structure of hyperbranched polymer which could decrease the chain entanglements in the network and compensate it with physical interactions such as $\mathrm{H}$-bonding. In another attempt, it was indicated that polyhedral oligomeric silsesquioxane could significantly enhance the scratch resistance and general healing of acrylic melamine clearcoat. ${ }^{30}$ Such improvements were assigned to the compact organic/inorganic structure of silsesquioxane building blocks which could provide dispersed nanoscale scaffolds within the matrix. Nano-scale reinforcement was achieved via both physical and covalent interactions of silsesquioxane nano-cages. As stated earlier, increased molecular reinforcement at high loading of silsesquioxane led to an increased brittleness of the clearcoat which was reflected in the tensile properties and several rupture on the scratch profile of the clearcoat. ${ }^{30,31}$ It was shown that these ruptures left on the clearcoats after healing treatment. Such permanent failures on the clearcoat surface deface the appearance in short times and threaten the barrier properties of the clearcoat from a long-term viewpoint. ${ }^{41-43}$

This work intends to simultaneously employ both hyperbranched polymer and silsesquioxane nano-cages to modify acrylic melamine network to achieve high scratch resistance and high healing capabilities. We aim to employ these unique characteristics together to develop a hard/flexible coating via tuning the chemical and physical cross-linking in the clearcoat network.

\section{Experimental}

\subsection{Materials and methods}

The clearcoat employed was based on an acrylic/melamine resin in which $\mathrm{OH}$-functional groups of the acrylic resin react with the alkoxy groups of the melamine cross-linker. Acrylic resin (Tacryl 765ZA provided from TAAK resin, Iran, $M_{\mathrm{w}}=13000 \mathrm{~g} \mathrm{~mol}^{-1}$, hydroxyl content of $4.2 \%$ ) and partially butylated melamine formaldehyde resin (Tacmine 564N) with a weight ratio of
$70: 30$ (acrylic : melamine) was considered as the basis of formulation. Two nano-structured modifiers were utilized to formulate the clearcoats namely a polyhedral oligomeric silsesquioxane and a hyperbranched polymer which both contained OH-functional groups. The polyhedral oligomeric silsesquioxane compound, AL-0136 (POSS) was based on octa(3hydroxy 3-methyl butyl dimethyl siloxy) structure, procured from Hybrid Plastic Inc. The hyperbranched polymer (HBP), Hybrane H-1500 procured from DSM, has a polyester-amide backbone with a theoretical molecular weight of $1500 \mathrm{~g} \mathrm{~mol}^{-1}$. The general structures of POSS and HBP are presented in Fig. 1. The clearcoat formulation was modified in such a manner to partially replace $\mathrm{OH}$-functionals of acrylic resin with those of POSS and HBP. The replacement was stoichiometrically performed according to the molar weight range over which POSS and HBP modifiers had delivered the best performance as reinforcing and toughening agents, respectively. It has been revealed that the best toughening properties were obtained when less than $10 \%$ of $\mathrm{OH}$ functionals of acrylic were substituted with those of HBP. In case of POSS, it was revealed that the scratch resistance increased as POSS content increased up to the amount that $25 \%$ of $\mathrm{OH}$ functionals of acrylic was replaced with those of POSS. Therefore, the following sample coding is utilized in this paper. $\mathrm{H} x \mathrm{P} y$ represents the clearcoat formulation in presence of HBP and POSS where " $x$ " and " $y$ " respectively denote the mole percentage of $\mathrm{OH}$ functional groups of acrylic which have been replaced with those of HBP and POSS in the formulation. " $x$ " is 5 or 10 and " $y$ " varies from 5 to 25 .

HBP and POSS were separately dissolved in methyl ethyl ketone (MEK) and butyl acetate and then were added to the acrylic/melamine solution. The clear solutions were readily soluble in each other. Table 1 lists the main ingredients used in each modified clearcoat.

Some additives including acid catalyst $(1.5 \mathrm{wt} \%$ of total formulation, para-toluene sulfonic acid, PTSA) and defoamer (0.2 wt\% of total formulation, Delta-FC 1040) were also added to the clearcoat formulations. All formulations were then mixed for 60 min using a high shear stirrer. The liquid formulations were quite transparent. By the means of film applicator, the modified clearcoats were applied on pre-cleaned glass substrates. Samples were then cured at $140{ }^{\circ} \mathrm{C}$ for $25 \mathrm{~min}$. The thickness of cured films was $65 \pm 5 \mu \mathrm{m}$. The glass coated substrates were immersed in water and removed after 5 min to prepare free films for dynamic mechanical thermal analysis (DMTA).

\subsection{Characterization}

The micro-scratch tests were performed using a Rockwell indenter (tip radius $=800 \mu \mathrm{m}$ ) mounted on a CSM Micro-Combi tester instrument. The scratch test was conducted through a three-stage mode; pre-scan, scratching and post-scan. First, the indenter applied a low load $(20 \mathrm{mN})$ on the surface to record the surface profile (pre-scan). For scratching, a progressive normal force from 20 up to $15000 \mathrm{mN}$ at a constant rate (around $4996 \mathrm{mN} \mathrm{min}^{-1}$ ) was applied to the clearcoat surface and $6 \mathrm{~mm}$-long scratches were made at a rate of $1 \mathrm{~mm} \mathrm{~min}^{-1}$. 


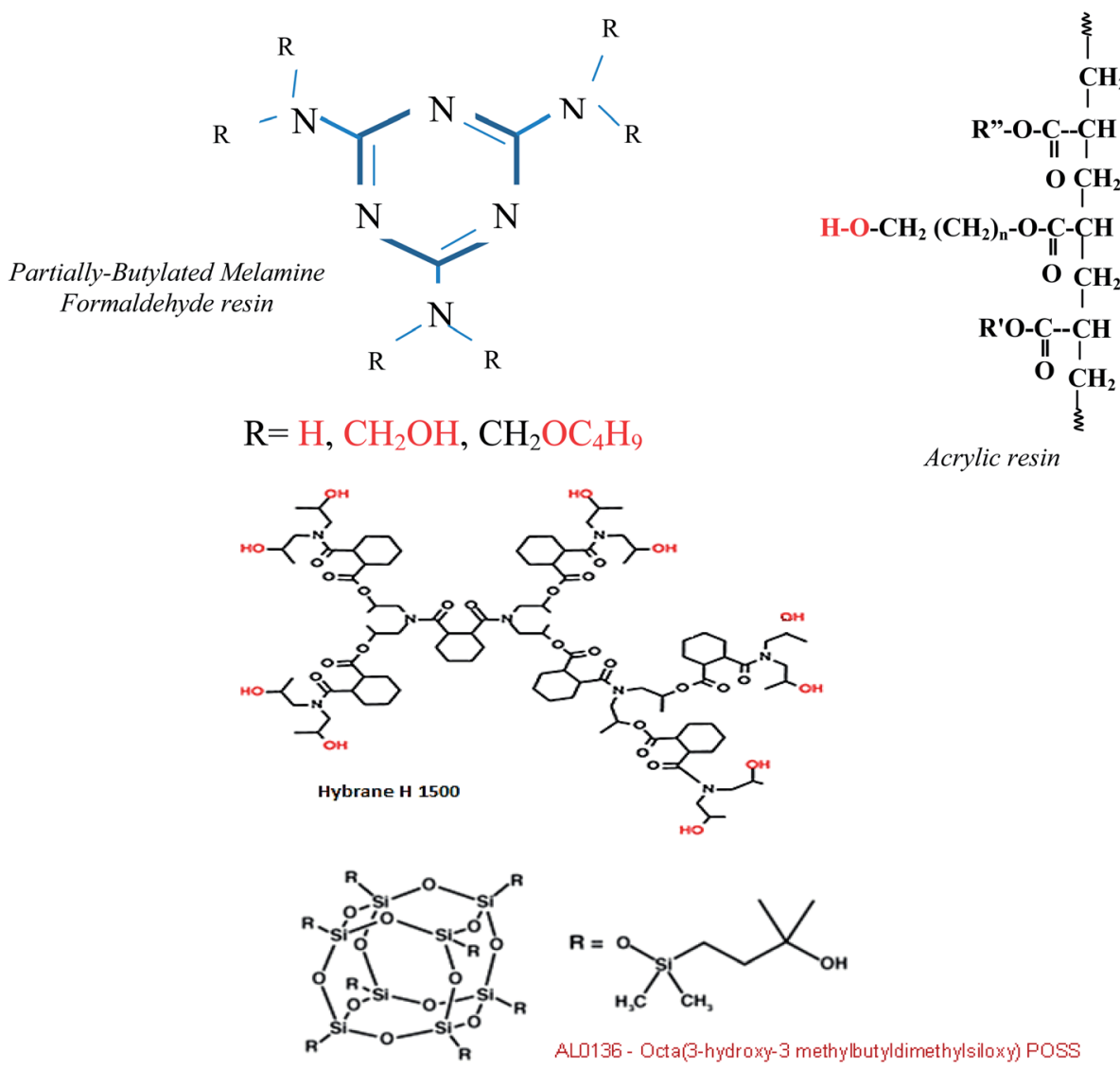

Fig. 1 Chemical structure of acrylic, melamine, HBP and POSS components used in clearcoat formulations.

Finally, the indenter applied a low load $(20 \mathrm{mN})$ on the scratched surface to record the scratch trace (post-scan). The three-stage process was replicated 3 times for each sample. The resultant scratches were studied directly by the aid of an optical microscope to find the position of the first and second (if any) critical forces (abbreviated as FCF and SCF respectively). FCF is the force at which the scratch trace becomes visible while SCF is the lowest force which causes coating rupture.

Micro hardness of the clearcoats containing various loads of POSS and HBP was determined using a Leica VMHTMOT microindenter equipped with a Berkovich diamond tip (3-faced pyramid) according to the following equation:

$$
H=1854.4 \times P / d^{2}
$$

Table 1 The main ingredients used in each modified clearcoat

\begin{tabular}{lllll}
\hline Sample code & Acrylic $(\mathrm{g})$ & Melamine $(\mathrm{g})$ & HBP $(\mathrm{g})$ & POSS $(\mathrm{g})$ \\
\hline H0P0 & 70.00 & 30.00 & 0.00 & 0.00 \\
H5P5 & 61.81 & 30.00 & 1.27 & 1.81 \\
H5P15 & 54.94 & 30.00 & 1.27 & 5.44 \\
H5P25 & 48.07 & 30.00 & 1.27 & 9.06 \\
H10P5 & 58.37 & 30.00 & 2.55 & 1.81 \\
H10P15 & 51.51 & 30.00 & 2.55 & 5.44 \\
H10P25 & 44.64 & 30.00 & 2.55 & 9.06
\end{tabular}

where $H$ is hardness, $P$ is the applied load and $d$ is the diagonal Vickers indentation. A normal force of $19.6 \mathrm{~N}$ was applied for 15 seconds.

After scratch test, the profile of the scratched surface was recorded by confocal profilometry (Conscan profilometer, CSM Instruments) which had been mounted and attached to the scratch test device as an accessory. After recording scratch data, the scratched surfaces of various clearcoats were subjected to a thermal healing process. The samples were kept at $100{ }^{\circ} \mathrm{C}$ for around $8 \mathrm{~h}$. This temperature was chosen because it was near the glass transition temperature of clearcoats. After the healing process, the samples were again mounted on the scratching machine (exactly at the same position of the healed scratches) to conduct a scratch run.

The profilometry technique was again used to record the profile of healed scratches. In order to correlate scratch and healing data with structural characteristics of clearcoats, various analytical techniques including DMTA, FTIR and surface free energy measurements were also performed. The effect of modifiers addition on cross-linking density and glass transition temperature $\left(T_{\mathrm{g}}\right)$ was studied by the aid of a Q800 (TA instrument, USA) dynamic mechanical thermal analyzer (DMTA). Experiments were carried out in a tension mode on free films at $1 \mathrm{~Hz}$. The heating range was 25 to $200{ }^{\circ} \mathrm{C}$ and the heating rate was $5{ }^{\circ} \mathrm{C} \mathrm{min}^{-1}$ (according to ASTM E1640-04). Cross-linking density was calculated from rubbery plateau 
zone of storage modulus $\left(\nu_{\mathrm{e}}=E / 3 R T\right)$ where $\nu_{\mathrm{e}}$ is cross-linking density and $R$ is gas constant. $E$ and $T$ are storage modulus and temperature at the initial point of rubbery zone, respectively.

In order to follow H-bonding variations of clearcoats in presence of HBP and POSS, FTIR spectroscopy was performed. A Perkin Elmer Spectrum ${ }^{\mathrm{TM}}$ One FTIR Spectrometer model IFS48 was utilized for this purpose.

Surface free energy for different modified clearcoats was calculated by $\mathrm{Wu}$ method. This method utilizes the contact angle data of at least two probe liquids. We, however, used three liquids (water, formamide, diiodomethane) to calculate the surface free energy of each clearcoat. It was performed by the aid of an OCA 15 contact angle measurement instrument (Dataphysics Co.) which was equipped with a CCD camera to record the contact image.

\section{Results and discussion}

The main purpose of introducing POSS and HBP nanostructures into automotive clearcoats, was enhancing the scratch resistance and healing efficiency of the resultant coatings. Scratching behavior of the blank and all modified clearcoats was investigated by means of a scratch tester. An optical microscope with magnification of $5 \times$ was used to find the position of FCF and SCF for each clearcoat. Fig. 2 depicts the optical images of all clearcoat surfaces after scratch testing. General overview of this figure reveals that incorporation of both nanostructures into clearcoat (especially at high portions) shows enhancement against scratch. It is also observed that while there are some ruptures at low loading of POSS (i.e. H5P5 and H10P5, H10P15), these are absent on the clearcoats loaded with high contents of POSS. The scratch behavior is quantified in terms of critical applied normal forces; FCF and SCF. Due to the importance of visual aspect of scratches, the lowest force producing a visible deformation on the surface can be considered as a quantitative criterion for scratch resistance. Therefore, the FCF value of clearcoats was regarded as the scratch resistance. $^{\mathbf{4 , 4 4}}$ In addition, occurrence of any rupture during scratching can reflect the maximum endurance of clearcoat against applied force beyond which the coating is torn. ${ }^{4}$ The SCF value reflects the ductility of the coating and is highly critical from healing viewpoint. The FCF and SCF values for all clearcoats are listed in Table 2 . The data reported in this table are the mean values obtained from at least 3 scratch experiments.

As clearly seen in Fig. 2 and Table 2, it is obvious that addition of POSS and HBP into clearcoat formulations increases their scratch resistance. Among different clearcoats, as the POSS content increases, the FCF (scratch resistance) shifts to higher values. In case of SCF, while the nanocomposite coatings containing low loadings of POSS are torn during scratch testing,

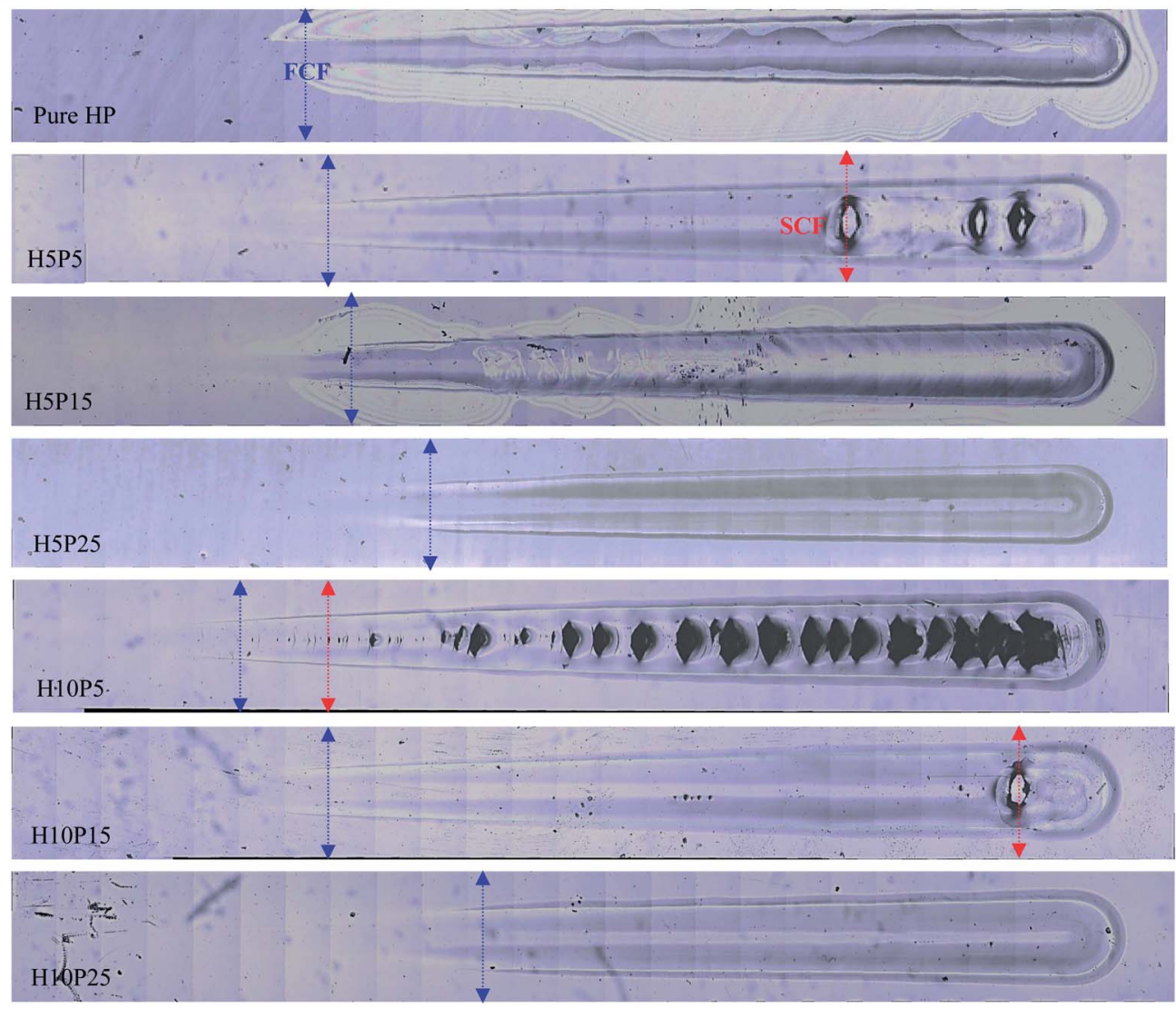

Fig. 2 Optical images of scratched surfaces of various clearcoats loaded with different contents of POSS and HBP nanostructures. 
Table 2 FCF, SCF and recovery values at 1 and $10 \mathrm{~N}$ for various modified clearcoats

\begin{tabular}{|c|c|c|c|c|c|c|c|}
\hline \multirow[b]{2}{*}{ Parameter } & \multicolumn{7}{|l|}{ Sample } \\
\hline & HOP0 & H5P5 & H5P15 & H5P25 & H10P5 & H10P15 & H10P25 \\
\hline $\operatorname{SCF}(\mathrm{N})$ & Not seen & 10.52 & Not seen & Not seen & 4.88 & 14.18 & Not seen \\
\hline Penetration depth at $2.5 \mathrm{~N}(\mu \mathrm{m})$ & $10.64 \pm 1.22$ & $9.01 \pm 1.2$ & $12.59 \pm 0.6$ & $12.73 \pm 1.4$ & $13.72 \pm 2.2$ & $12.71 \pm 0.8$ & $34.24 \pm 3.2$ \\
\hline Residual depth at $2.5 \mathrm{~N}(\mu \mathrm{m})$ & $0.96 \pm 0.2$ & $0.79 \pm 0.1$ & $0.79 \pm 0.12$ & $0.44 \pm 0.06$ & $1.13 \pm 0.2$ & $1.19 \pm 0.2$ & $0.39 \pm 0.1$ \\
\hline Residual depth at $10 \mathrm{~N}(\mu \mathrm{m})$ & $5.88 \pm 0.18$ & $7.40 \pm 0.42$ & $6.36 \pm 0.36$ & $8.47 \pm 0.22$ & - & $11.24 \pm 0.24$ & $9.83 \pm 0.58$ \\
\hline Recovery at 10 N (\%) & 0.90 & 0.77 & 0.85 & 0.83 & Not definable & 0.82 & 0.80 \\
\hline
\end{tabular}

the pristine clearcoat as well as the ones containing high loadings of modifiers (H5P15, H5P25, H10P25) do not experience any rupture in the whole range of applied force ( 0 to $15 \mathrm{~N}$ ).

These results clearly reveal that clearcoats containing the highest content of modifiers such as H5P25 and H10P25 have the highest values of scratch resistance. For H5P25 and H10P25 a scratch resistance improvement around 1.94 and 2.35 times was achieved by addition of only $10 \mathrm{wt} \%$ of POSS and $1 \mathrm{wt} \%$ of HBP. Another feature of this modification is that such a high level of improvement was obtained with no rupture in the scratch groove. This is promising from a healing point of view. It was revealed in our previous studies that, incorporation of high loading of POSS nanostructures into the acrylic/melamine network (in absence of HBP) resulted in 1.88 times improvement in scratch resistance. But it led to a highly fragile network which was accompanied with occurrence of several rupture on the coatings during scratch test which negatively affected the healing performance. ${ }^{30}$ In this regards, it can be concluded that addition of low content of HBP to the formulation not only is an appropriate strategy to alleviate the extra reinforcing character of POSS building blocks and obtain a tough scratch resistant coating, but also leads to further improvement in scratch resistance.

An increase in hardness could be a possible mechanism for scratch resistance improvement. In order to verify this hypothesis, the hardness of various modified clearcoats was assessed by micro-indentation test. The hardness values of all clearcoats are presented in Fig. 3.

As seen in Fig. 3, while H5P5 clearcoat (containing the lowest modifiers content) has a comparable hardness with the blank sample, other modified clearcoats have lower hardness values. The trend of hardness variations clearly illustrates that as POSS and HBP content increases, the hardness diminishes. It was expected that due to organic/inorganic nature of POSS compounds, such a modification would led to a promotion in hardness. ${ }^{30,45,46}$ However, as seen, simultaneous incorporation of POSS and HBP into clearcoats not only did not increase the hardness, but also decreased it. The reason of such an unexpected finding will be thoroughly discussed in the DMTA results.

Hardness results obviously show that another mechanism other than surface hardening is involved in scratch resistance improvement. Elastic recovery, the ability of coating to get back (return) to its original state (position) immediately after being deformed by the indenter, ${ }^{12,25,44}$ may be the probable mechanism. Thus, this parameter was calculated by dividing the residual depth to the penetration depth. The penetration, residual depths and calculated elastic recovery values at 2.5 and $10 \mathrm{~N}$ are presented in Table 2 . The trend of penetration depths at both 2.5 and $10 \mathrm{~N}$ reveals that in comparison with neat clearcoat (H0P0), the penetration depth slightly decreases for clearcoats containing low loading of modifiers (H5P5 and H10P5) while it increases for higher loadings of modifiers (for H5P15, H10P15, H10P15 and H10P25). The comparison of penetration depth with hardness data (Fig. 3) demonstrates a relatively inverse relationship between penetration depth and hardness of the coatings which is rational. The lower hardness of the coating allows the indenter to penetrate deeper in the coating. Low and high forces were considered to respectively characterize the surface and bulk of the coatings. It is seen that the recovery value is the same at both surface and bulk of the blank sample which is plausible because of its relatively less complicated network. For nano-structured composites, however, the recovery values at their surface and bulk are different and this difference becomes more pronounced as the modifier content increases. Recovery values at $2.5 \mathrm{~N}$ (surface) illustrate that elastic recovery increases as the modifiers' content increases meaning that the surface become more elastic in presence of modifiers. In case of $10 \mathrm{~N}$ (bulk), elastic recovery seems to decline as the POSS content decreases,

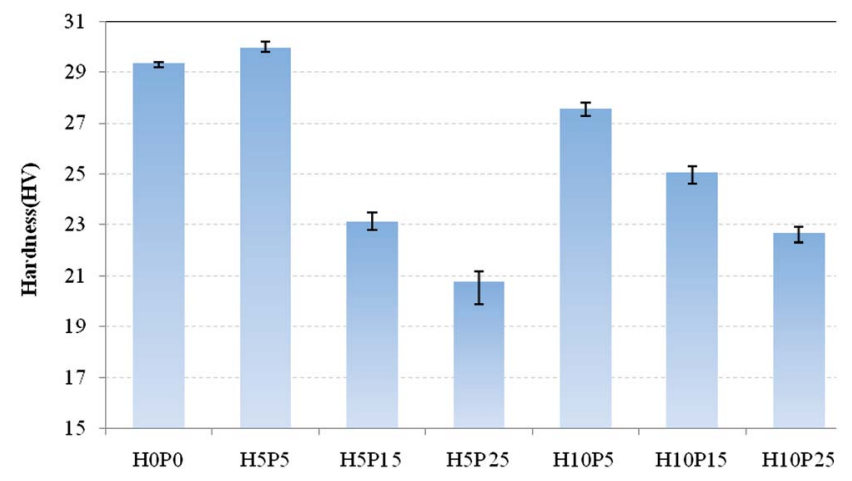

Fig. 3 Hardness values for blank and modified clearcoats. 
confirming that the bulk is converted to a tougher material. These results prove that simultaneous incorporation of POSS and HBP nanostructures leads to a clearcoat which is more elastic in surface and is tougher in its bulk. Such a graded structural composition is a favorable character for clearcoat because an elastic surface can provide a less deformed surface (increased scratch resistance) and the flexible tough bulk prevents from or postpone the permanent failures (polymeric chain ruptures) to higher applied forces by which enhance the chance of healing. Therefore, it can be demonstrated that elasticity enhancement is the possible mechanisms of scratch resistance improvement. The enhanced elasticity can be assigned to the organic/inorganic nature of POSS nanostructures and the high elasticity of Si-O- scaffold. ${ }^{25,30,47,48}$

\subsection{Healing studies}

The ability of different nano-structured coatings to heal the scratches formed on their surface was investigated after being exposed to a thermal healing process $\left(8 \mathrm{~h}\right.$ at $\left.100{ }^{\circ} \mathrm{C}\right)$. The optical images of scratched surfaces after healing process are given in Fig. 4. These images are the healed scratches shown earlier in Fig. 2 .

Comparison of the optical images of scratched and healed areas (Fig. 2 and 5) reveals that for all clearcoats, the scratch grooves have relatively disappeared and it seems that the surface has returned to its initial position notably. This can be indicative of an inherently good healing ability of acrylic/ melamine matrix which may be attributed to the polar structure of the melamine-based architecture. It is well known that, development of non-covalent interactions like ionic, polar and hydrogen bonding are of the most important mechanisms involved in the enhancement of healing ability of coatings..$^{7,10,11,49,50}$ It is due to the thermal reversibility of these interactions which provide this chance for polymeric chains to easily move and re-arrange during a thermal healing process. Numerous polar sites for physical and hydrogen bonding interactions have made melamine structure attractive to scientists to employ this structure for the applications where non-covalent interactions are desired (i.e. in the field of supramolecules $\left.{ }^{51-53}\right)$. Although melamine is used as a covalent cross-linker in most of thermosetting systems and is not free enough to behave like a perfect non-covalent component, it would be reasonable to believe that the capability of melamine in interacting via its polar groups or donating and accepting hydrogen bonding has an outstanding impact on the properties of melamine-based thermosetting polymers. ${ }^{29,32}$ Several $\mathrm{N}-\mathrm{H}, \mathrm{CH}_{2} \mathrm{OH}$ groups as $\mathrm{H}$-donors as well as various $-\mathrm{O}-,-\mathrm{N}=$ sites as $\mathrm{H}$-acceptors are available on the partially butylated melamine structure to form multiple hydrogen bonding between melamine itself or with acrylic chains. Therefore, this particular chemical structure can account for the high healing of these clearcoats.

General view of the healed scratches implies that while the main trace of scratch for all clearcoats has been relatively healed, some local parts of the scratch which have been ripped in scratching are still visible and it seems that they have not been healed. Fig. 4 clearly exhibits that while the scratch trace for the pristine clearcoat (sample H0P0) is still identifiable, it has been completely disappeared for nanocoatings, indicating a higher healing ability of nano-structured coatings compared to the blank clearcoat. It is also observed that for clearcoats

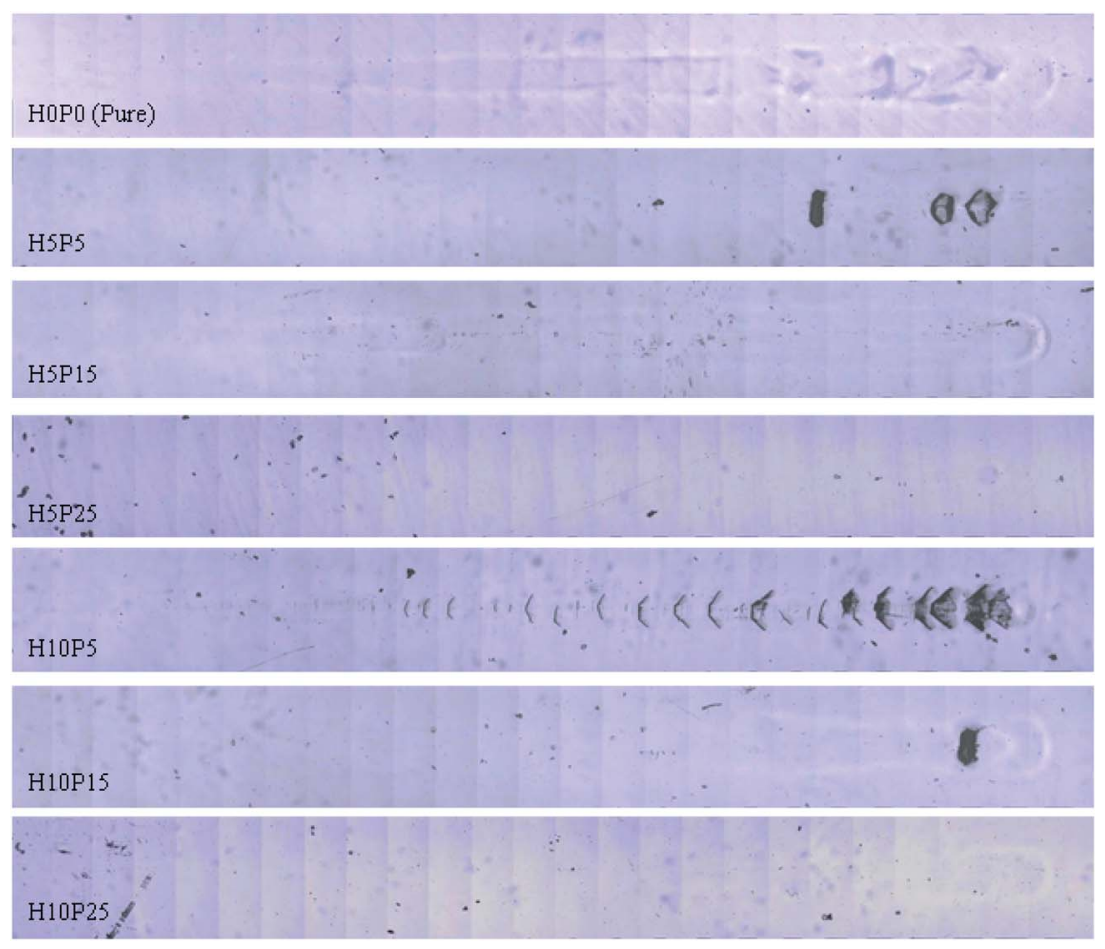



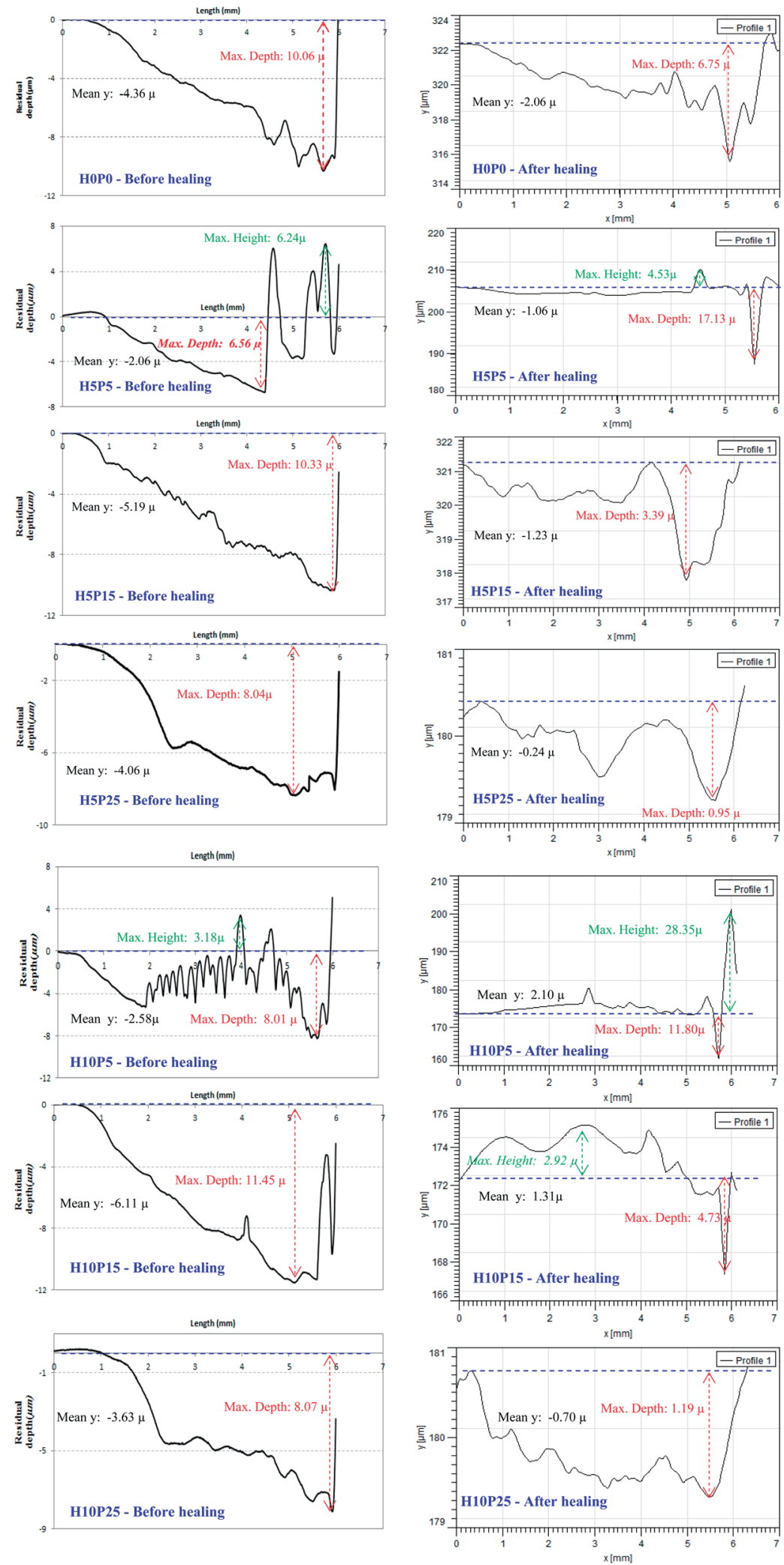

Fig. 5 The profile of the bottom of the scratches for different clearcoats before and after healing.

containing high loadings of HBP and POSS, i.e. H5P15, H5P25 and H10P25 which were the most scratch resistant samples and did not experience any rupture during scratch testing, the scratches have been fully healed.
The healing ability of coatings can be quantitatively judged based on the healing of the main trace of the scratch. In order to quantify the healing ability of the coatings, profilometry technique was utilized. The profile of the bottom of the scratch 
Table 3 Healing results obtained from the scratch profiles before and after healing process

\begin{tabular}{|c|c|c|c|c|c|c|}
\hline Sample & $\begin{array}{l}\text { Mean } y \\
\text { (bef.) }(\mu \mathrm{m})\end{array}$ & $\begin{array}{l}\text { Max. depth } \\
\text { (bef.) }(\mu \mathrm{m})\end{array}$ & $\begin{array}{l}\text { Mean } y \\
(\text { aft. })(\mu \mathrm{m})\end{array}$ & $\begin{array}{l}\text { Max. depth } \\
\text { (aft.) }(\mu \mathrm{m})\end{array}$ & $\begin{array}{l}\text { Healing according } \\
\text { to mean } y(\%)\end{array}$ & $\begin{array}{l}\text { Healing according } \\
\text { to max. depth }(\%)\end{array}$ \\
\hline HOPO & -4.36 & 10.06 & -2.06 & 6.75 & 52.7 & 32.9 \\
\hline H5P5 & -2.06 & 6.65 & -1.06 & 17.13 & 48.5 & Not definable \\
\hline H5P15 & -5.19 & 10.33 & -1.23 & 3.39 & 76.3 & 67.1 \\
\hline H5P25 & -4.06 & 8.04 & -0.24 & 0.95 & 94.0 & 88.1 \\
\hline H10P5 & -2.58 & 8.01 & 2.1 & 11.8 & Not definable & Not definable \\
\hline H10P15 & -6.11 & 11.45 & 1.31 & 4.73 & Not definable & 58.6 \\
\hline H10P25 & -3.63 & 8.07 & -0.7 & 1.19 & 80.7 & 85.2 \\
\hline
\end{tabular}

before and after healing was measured. These profiles are presented in Fig. 5. The profile is given as $y$ (altitude) against $x$ (scratch length). The values on the vertical axis, $y$ values, were assigned by the cone-scan software. Their absolute values are not important and therefore relative variations compared with their original surface (dashed lines) have to be considered. On each profile, the maximum $y$ (as depth), and the mean $y$ (the average of $y$ compared to the original surface) in micron was measured and presented in Table 3.

The profiles of the scratches after healing for unmodified clearcoat (H0P0) and those loaded with high content of modifiers (H5P15, H5P25 and H10P25) reveal that the depth of the scratch has significantly lowered. In case of other nano- structured clearcoats (H5P5, H10P5 and H10P15), it is seen that in most part of the profile, the scratched surface has returned to its original state (dashed lines), but there are some local areas that the surface profile are significantly deviated from original surface. These are those areas which had been torn during scratch and have not been healed during thermal treatment process and have remained on the coating surface as permanent deep holes or high hills.

The best two criteria to quantify the healing efficiency could be the variations in maximum depth or average of $y$ before and after healing process. Therefore, healing efficiencies according to recovery of maximum depth and mean $y$ during healing have been calculated and presented in Table 3 .
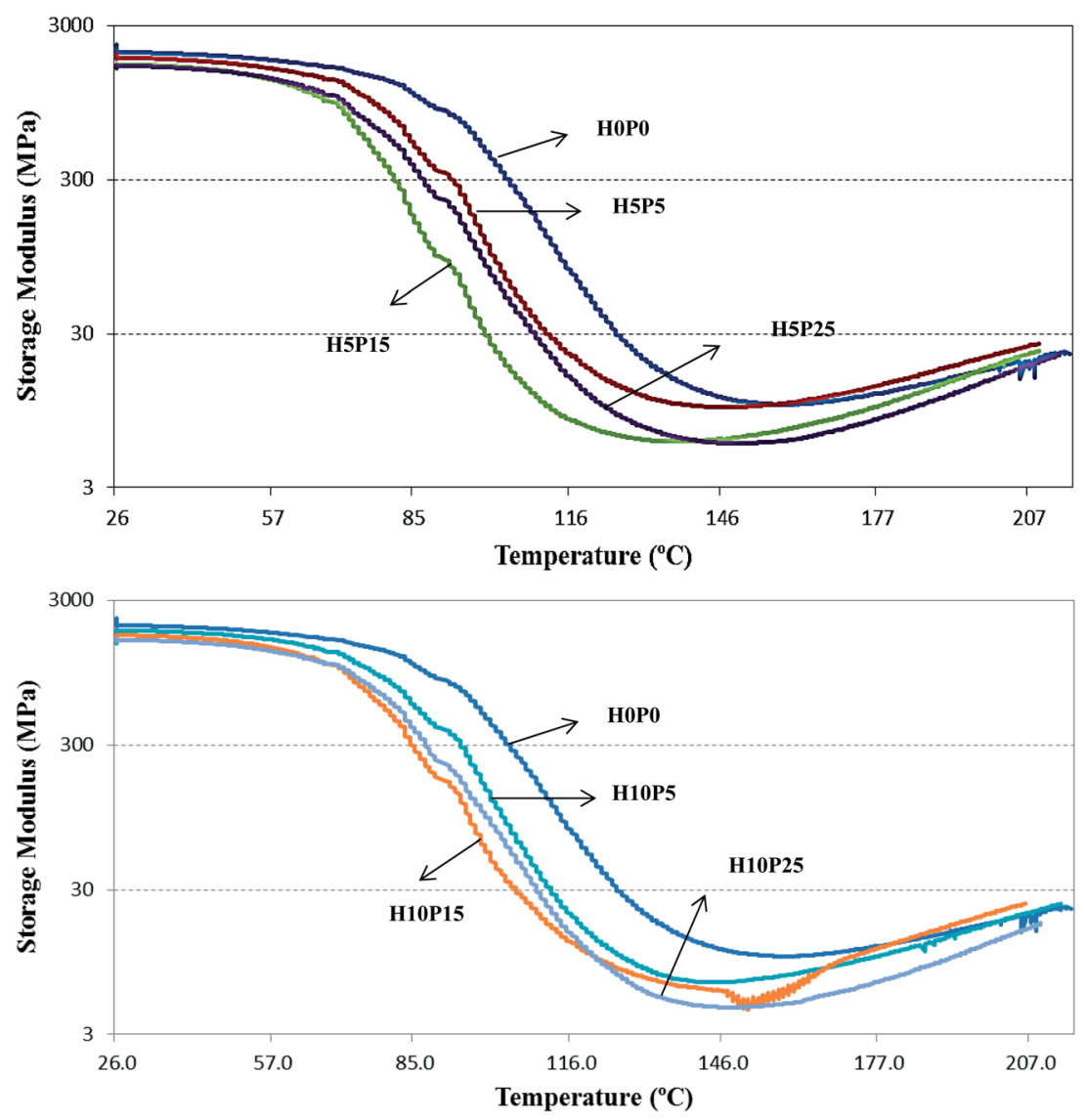

Fig. 6 Variations of storage modulus versus temperature for different clearcoats. 
The healing ability of different coatings in Table 3 clearly shows that all clearcoats modified with HBP and POSS nanostructures have a much higher ability to heal the scratches. The healing efficiency increases as the modifier content, especially POSS nanostructures, increases. The higher healing ability of modified clearcoats is in such a way that the scratch has been fully healed and the initial scratch trace is not identifiable. The healing performance of clearcoats will be thoroughly discussed later in DMTA section where the basic structural parameters of clearcoats are illustrated.

\subsection{Structure-property correlations}

DMTA experiments were performed to study structural characteristics such as cross-linking density (XLD), $T_{\mathrm{g}}$ and homogeneity of modified clearcoats. Variations of storage modulus and $\tan \delta$ versus temperature are depicted in Fig. 6 and 7.

The loss factor $(\tan \delta$ ) curves (Fig. 7) for H0P0 and all modified clearcoats are similar, exhibiting a single uniform peak. This reflects the high compatibility between POSS and HBP with acrylic melamine matrix which forms a uniform single phase.

Different structural characteristics deduced from DMTA graphs such as storage modulus at $27^{\circ} \mathrm{C}$, cross-linking density (XLD), $T_{\mathrm{g}}$ and $\tan \delta$ width (as homogeneity factor) are given in Table 4. $T_{\mathrm{g}}$ values obtained from DSC experiments have also been included in Table 4 for comparison purpose.
As seen in Table 4, incorporation of both HBP and POSS leads to a decline in total XLD of the clearcoat. The higher modifiers the clearcoat contained, the lower was the XLD. $T_{\mathrm{g}}$ variations of the samples also reveal that while at low and moderate loadings of modifiers (H5P5, H10P5, H5P15 and H10P15) $T_{\mathrm{g}}$ decreases, it slightly increases for high loadings of modifiers (H5P25 and H10P25), but still lower than that of the unmodified clearcoat.

For comparison purpose, $T_{\mathrm{g}}$ values of different coatings were also defined using DSC experiments. The most frequent criterion (intersection of extrapolated baseline at onset temperature and the tangential line at the maximum slope of endothermic peak) was used to determine $T_{\mathrm{g}}$ (Table 4). It is observed that there is a difference around $40-50{ }^{\circ} \mathrm{C}$ between $T_{\mathrm{g}}$ values obtained from DSC with those deduced from DMTA experiments. In polymeric material characterization, such difference is common because of different test sensitivity and criteria employed to define $T_{\mathrm{g}}$ from DSC and DMTA experiments. Regardless of this difference, it is observed that $T_{\mathrm{g}}$ variations with addition of HBP and POSS obtained from DSC runs are well correlated with those deduced from DMTA technique.

In case of $\tan \delta$ width, as homogeneity factor, modification of clearcoat leads to an increase in $\tan \delta$ width, meaning a decrease in homogeneity of the coatings.

In order to find out the reason for the variations in crosslinking density and $T_{\mathrm{g}}$ of the modified clearcoats, it is
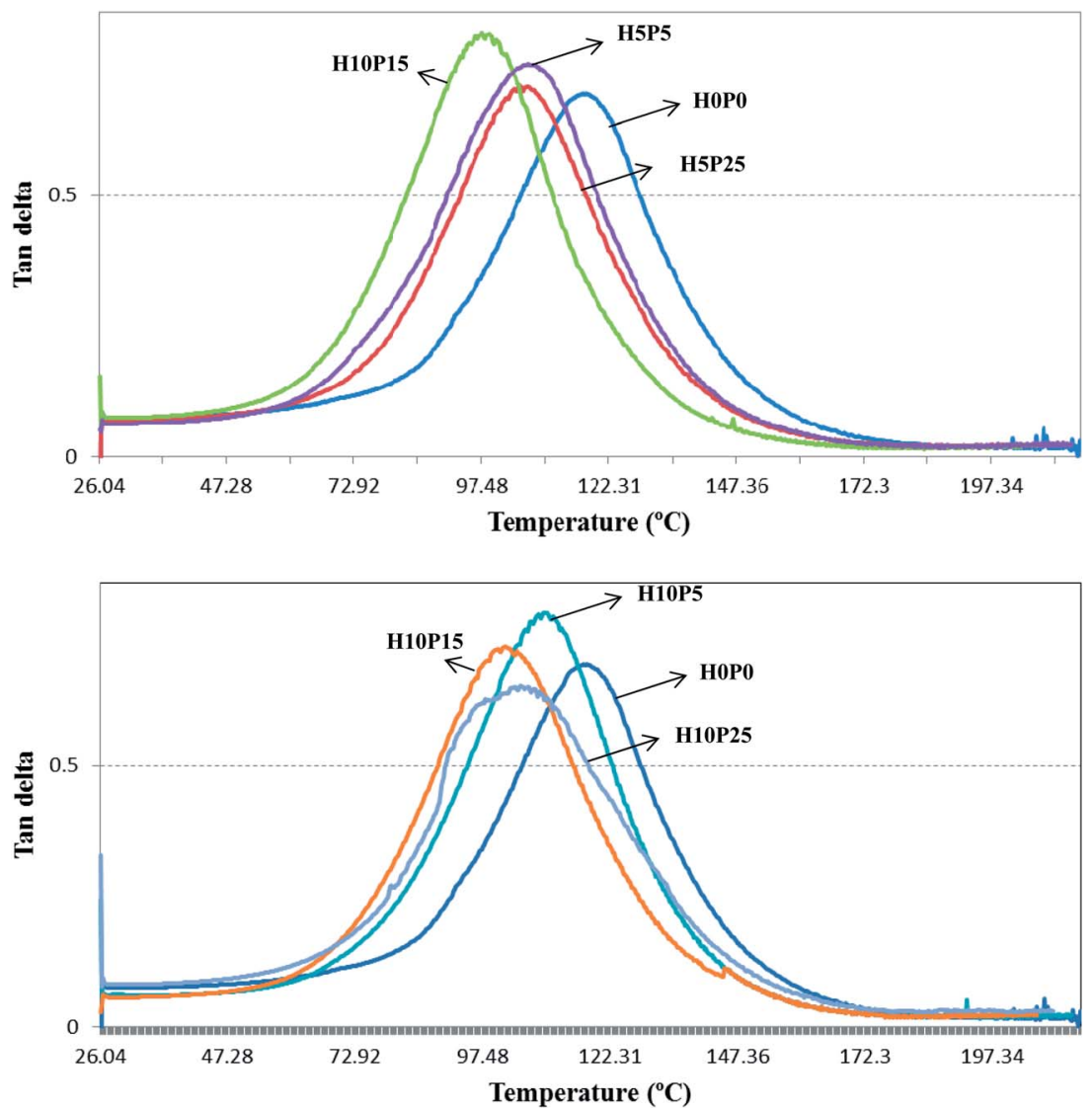

Fig. 7 Variations of $\tan \delta$ versus temperature for different clearcoats. 
Table 4 Some basic characteristics of clearcoats obtained from DMTA diagrams

\begin{tabular}{lllll}
\hline & & & & $\tan \delta$ \\
Sample code & XLD $\left(\mathrm{mmol} \mathrm{cm}^{-3}\right)$ & $T_{\mathrm{g}}\left({ }^{\circ} \mathrm{C}\right)$ & $T_{\mathrm{g}}{ }^{a}\left({ }^{\circ} \mathrm{C}\right)$ & width $\left({ }^{\circ} \mathrm{C}\right)$ \\
\hline H0P0 & 0.961 & 116.2 & 66.6 & 40 \\
H5P5 & 0.942 & 109.2 & 63.4 & 39 \\
H5P15 & 0.582 & 103.6 & 61.2 & 39 \\
H5P25 & 0.551 & 108.6 & 62.1 & 44 \\
H10P5 & 0.652 & 110.5 & 63.8 & 40 \\
H10P15 & 0.533 & 103.7 & 62 & 41 \\
H10P25 & 0.433 & 108.3 & 62.8 & 63 \\
${ }^{a} T_{\mathrm{g}}$ obtained from DSC experiments. & &
\end{tabular}

required to investigate the effect of HBP and POSS additions on the curing performance of the clearcoat. Utilizing thermomechanical and chemo-rheological techniques, the curing of modified clearcoats was thoroughly studied, but not stated here. In short, it was found that incorporation of HBP and POSS into clearcoat had two opposite effects on the curing degree. Due to more globular structure and lower molecular mass of HBP and POSS structures in comparison with linear acrylic polymeric chain, there is less extensive chain entanglements, leading to easier motion and lower viscosity. On the other hand, incorporation of HBP and POSS decreased the overall reactivity of formulation. It is because of this fact that the hydroxyl groups of acrylic resin are primary alcohols, while those of HBP and POSS are secondary and tertiary ones, respectively. It is well known that, due to spatial hindrance, the secondary and tertiary alcohols are less reactive compared to primary alcohols. Viscosity reduction is in favor of curing while reactivity reduction is against it. It was finally concluded that reactivity effect was more influential than the viscosity effect, leading to less efficient curing process and less chemically cross-linked network. Therefore, the reduced XLD of clearcoats containing HBP and POSS compared to the blank one can be attributed to the less proceeded curing reactions in presence of modifiers.

Lower $T_{\mathrm{g}}$ of modified clearcoats compared to that of pristine one can be assigned to the less entangled (due to compact structure of both modifiers) and less cross-linked network which produces a more flexible structure. ${ }^{54-56}$ In addition, increased $T_{\mathrm{g}}$ of clearcoats modified with high loadings of modifiers (H5P25 and H10P25) in spite of decreased values of their cross-linking density, implies that there are other forms of interactions such as physical and hydrogen bonding (rather than covalent bonding or chain entanglements) have to be taken into consideration.

Decreased cross-linking density leaves unreacted functional groups in the coating structure which can effectively interact with the surrounding sites via physical bonding such as H-bonding. Therefore, the enhanced $T_{\mathrm{g}}$ values for H5P25 and H10P25 may be explained through hydrogen bonding of unreacted functional groups remained on the coating structure.

Now, the main structural parameters i.e. XLD and $T_{\mathrm{g}}$ of blank and modified clearcoats are known. Therefore, it is possible to discuss the enhanced self-healing performance of clearcoats in presence of POSS and HBP macromolecules. Both modifiers have numerous sites on their globular structures to interact with their peripheral groups. Silsesquioxanes have various $\mathrm{Si}-\mathrm{O}-\mathrm{Si}$ linkages on the cage and also on the arms together with eight hydroxyl groups on its peripheral parts and is expected to have much more available sites to form hydrogen bonding with each other or with other components present in the clearcoat formulation (e.g. melamine resin). The HBP used, Hybrane 1500, has a polyester-amide backbone in its interior part (numerous ester and amide linkages) and has 10 hydroxyl groups on its peripheral parts. Similar to POSS, HBP can also develop H-bonding in the coating structure. Fig. 8 illustrates a schematic presentation of various possible $\mathrm{H}$-bonding interactions in a modified clearcoat composed of acrylic, melamine, HBP and POSS components and compares it with a blank acrylic/melamine clearcoat.

The co-monomers used in preparation of acrylic were styrene/methyl methacrylate/butyl methacrylate and 2-hydroxy ethyl methacrylate (HEMA). Despite relatively non-polar nature of these co-monomers which are weak or medium-strength in hydrogen-bonding formation (except for HEMA), HBP and POSS building blocks are highly capable to donate and/or accept $\mathrm{H}$ bonding. Fig. 8 clearly reveals how replacing an acrylic resin composed of less polar acrylate monomers with much more polar scaffolds (HBP and POSS) would significantly increase the intra- and inter-physical forces. It is seen that the chance of hydrogen bonding in presence of POSS and HBP is much more when they are absent in the formulation (blank clearcoat). Polarity and globularity of POSS and HBP nanostructures together with reduced XLD (which increased the portion of unreacted functional groups and thus, let the coating system interact via non-covalent forces instead of covalent ones) are three main characteristics which provide numerous and various sites around the modifiers peripheral to interact with each other and other components via hydrogen bonding.

These three characteristics allow the H-donor and $\mathrm{H}$-acceptors to be highly available. FTIR and surface energy results can provide some evidences to confirm the $\mathrm{H}$-bonding enhancement in the modified clearcoats. H-bonding is usually judged based on the shifts (for sharp peaks) or broadness (in case of broad peaks) of peaks corresponded to species involved in hydrogen bonding such as $-\mathrm{NH}$ and $-\mathrm{OH}$ ones. A part of FTIR spectra around $3200-3600 \mathrm{~cm}^{-1}$ which is assigned to various $-\mathrm{NH}$ and $-\mathrm{OH}$ groups of all clearcoats is shown in Fig. 9.

Presence of various $-\mathrm{NH}$ and $-\mathrm{OH}$ species on the chemical structure of modified acrylic/melamine clearcoats together with overlapping of $-\mathrm{NH}$ and $-\mathrm{OH}$ groups prevent precise characterization of hydrogen bonding. Due to such limitations, the general characterization can be done in literature in terms of the width of $-\mathrm{NH} \& \mathrm{OH}$ peak. For this purpose, the width at half height of $\mathrm{NH} \& \mathrm{OH}$ peak $\left(\Delta \nu_{1 / 2}\right)$ was measured. $\Delta \nu_{1 / 2}$ values for various modified clearcoats are presented in Table 5 .

The values of $\Delta \nu_{1 / 2}$ for various modified clearcoats clearly reveal that as HBP and POSS content increases, the width of $\mathrm{NH} \& \mathrm{OH}$ peak increases. Increase in broadness of this peak can reflect the contribution of different hydrogen-bonded $\mathrm{NH} \& \mathrm{OH}$ groups in the structure. This confirms the higher chances of 

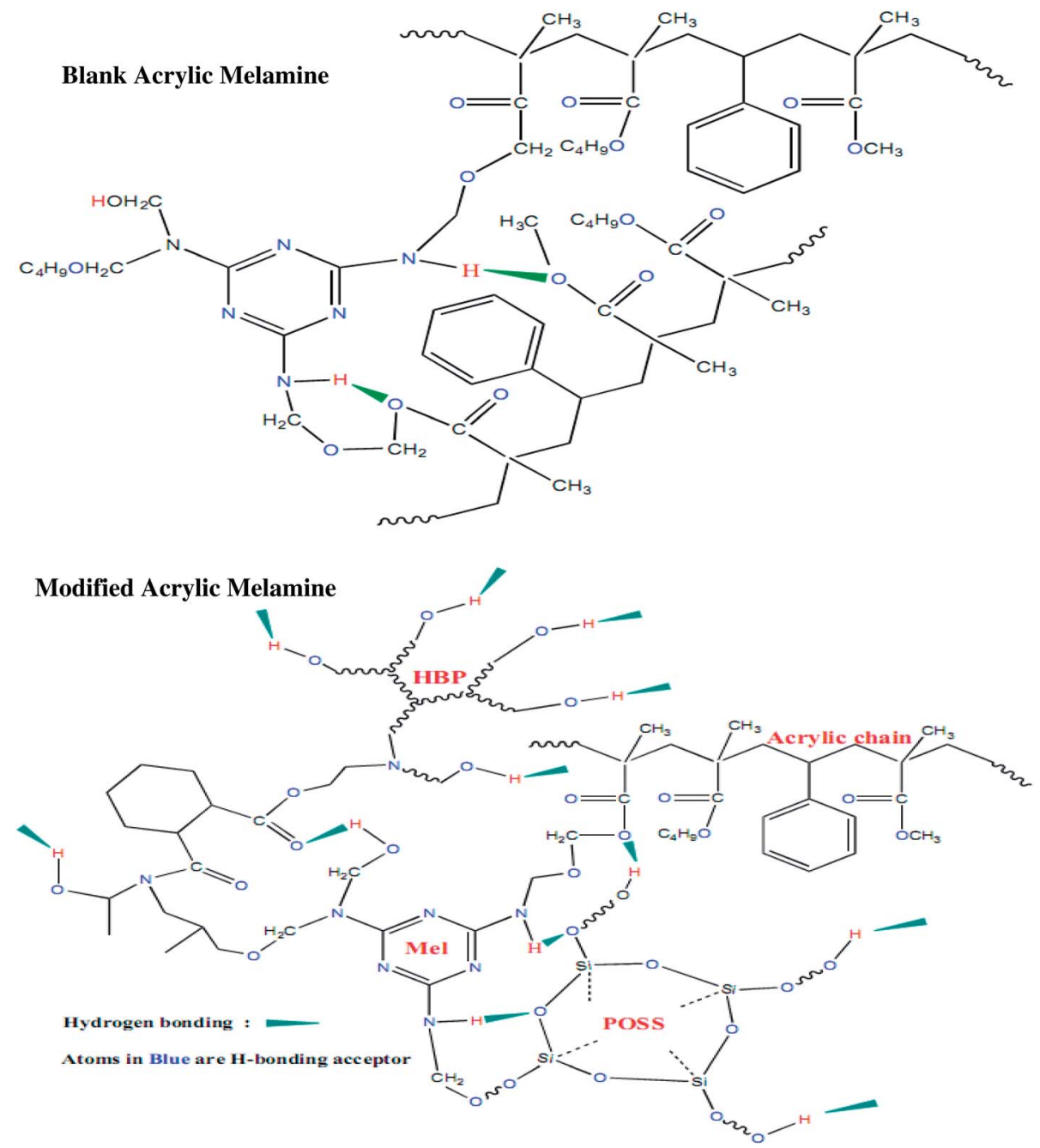

Fig. 8 Schematic presentation of various possible $\mathrm{H}$-bonding interactions in blank and a clearcoat modified with HBP and POSS.

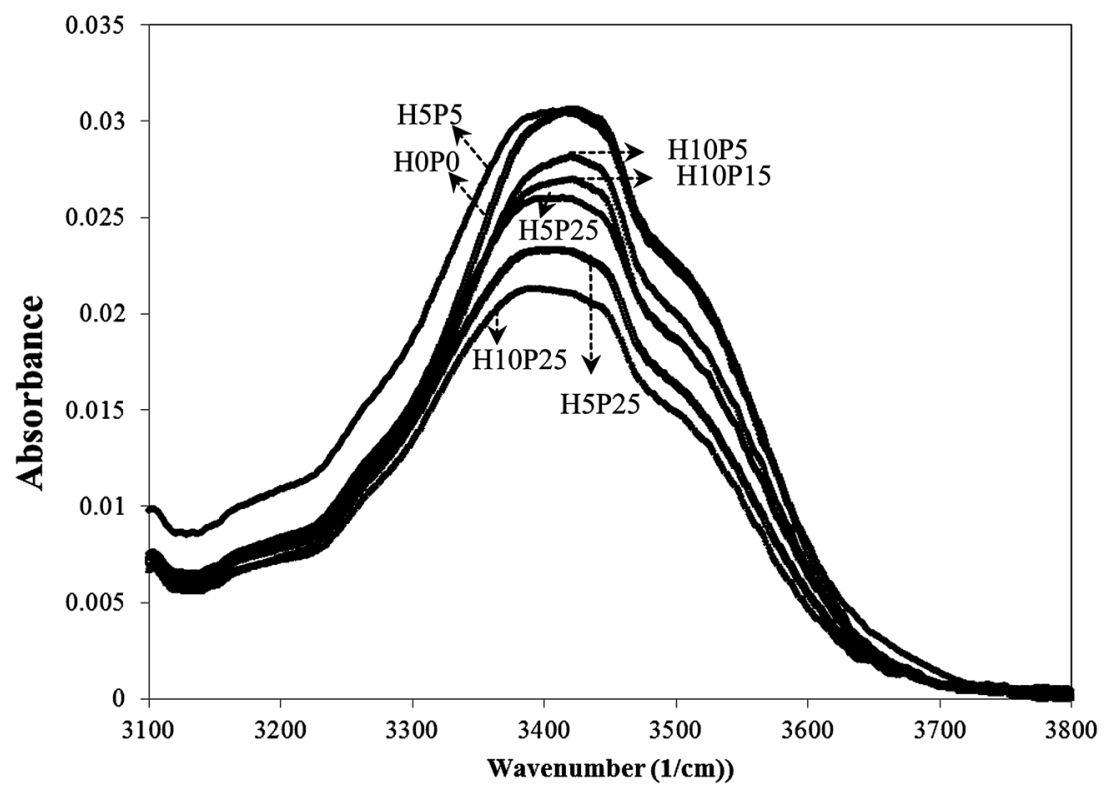

Fig. $9 \mathrm{NH}$ \&H peak of all clearcoats containing various loadings of POSS and HBP. 
Table 5 The width at half height of $\mathrm{NH} \& \mathrm{OH}$ FTIR peak $\left(\Delta \nu_{1 / 2}\right)$ for various clearcoats

$\begin{array}{llllllll}\text { Sample } & \text { H0P0 } & \text { H5P5 } & \text { H5P15 } & \text { H5P25 } & \text { H10P5 } & \text { H10P15 } & \text { H10P25 } \\ \left(\Delta \nu_{1 / 2}\right) & 237 & 242 & 247 & 248 & 238 & 241 & 247\end{array}$

Table 6 Surface free energy data for different modified clearcoats

\begin{tabular}{llll}
\hline Sample & Polar & Disperse & Total \\
\hline H0P0 & 12.63 & 18.3 & 30.93 \\
H5P5 & 12.31 & 18.49 & 30.79 \\
H5P15 & 12.92 & 17.18 & 30.09 \\
H5P25 & 19.08 & 16.52 & 35.61 \\
H10P5 & 11.84 & 18.97 & 30.81 \\
H10P15 & 13.65 & 18.05 & 31.69 \\
H10P25 & 14.15 & 17.83 &
\end{tabular}

hydrogen bonding in presence of HBP and POSS nanostructures, as discussed earlier. In addition to FTIR data, surface free energy data present interesting results. Surface free energy data including polar and disperse components for different modified clearcoats are given in Table 6 .

Table 6 clearly reveals that the total surface free energy for all modified clearcoat is higher than that of the neat one. As the modifiers content increases, the total surface free energy increases. Considering the polar and disperse components reveals that POSS and HBP incorporation results in a decrease in disperse part and meanwhile an increase in polar part of the clearcoat. It is observed that all POSS- and HBP-containing clearcoats have a much higher polar part in comparison with the blank clearcoat, especially those loaded with high contents of modifiers like H5P25 and H10P25 samples which had previously exhibited the highest level of healing. Increased polarity in presence of POSS and HBP may confirm again the change in nature of interactions in presence of POSS and HBP building blocks.

The increased contribution of reversible polar interactions such as hydrogen bonding as well as promoted flexibility (thank to reduced $T_{\mathrm{g}}$ and XLD) in modified clearcoats accounts for their high capability to heal the scratches. The interesting fact about this modification refers to the insignificant influence on the mechanical aspects of the clearcoats at ambient temperatures. Back to Fig. 6 (storage modulus vs. temperature) shows that such modification reduces the storage modulus at high temperature which is in favor of healing performance. Fortunately, the reduced storage modulus at ambient temperature (which is the service temperature of an automotive coating) is not significant. This refers to the thermal sensitivity of $\mathrm{H}$-bonding. While $\mathrm{H}$-bonding contributes to the increased interchains interaction and thus mechanical properties at low temperatures, the elimination of $\mathrm{H}$-bonding at high temperatures let the polymeric chains move and rearrange and therefore, healing performance enhances.

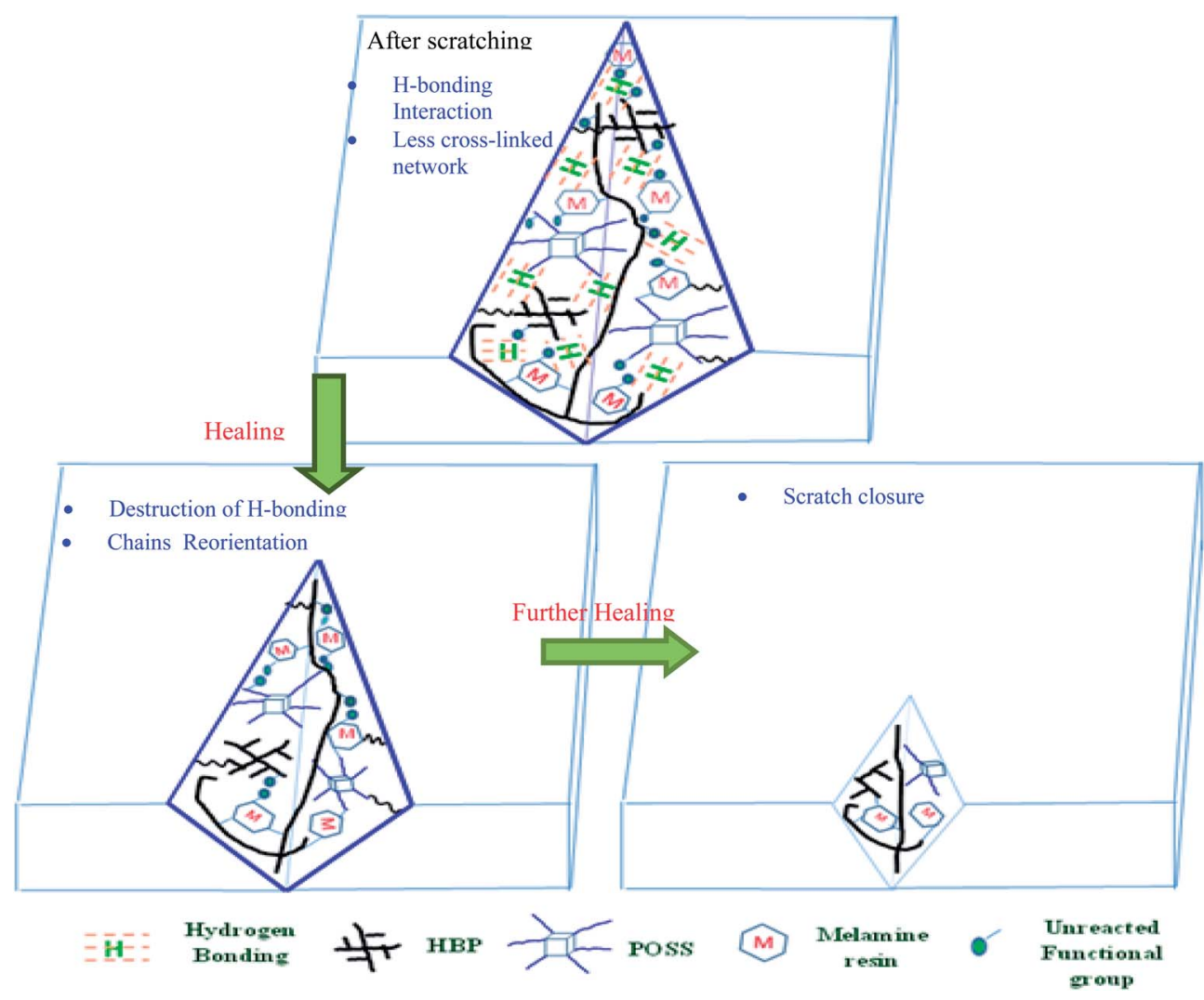

Fig. 10 Schematic illustration of enhanced healing in presence of HBP and POSS. 
According to all findings, Fig. 10 schematically illustrates how a modified clearcoat heals itself.

The plenty of physical interactions like H-bonding which are thermally sensitive can provide a high level of healing during a thermal treatment process. The increased level of physical interaction reorients potentially the chains at elevated temperatures. At higher temperatures, the polymeric chains are released from $\mathrm{H}$-bonding interactions and therefore, can move more easily and be rearranged. Such a re-arrangement at elevated temperature can partially or fully reform a deformed area (like a scratched surface) to its original state. Beside three characteristics mentioned above (polarity, globularity of POSS and HBP nanostructures together with reduced XLD), there is another important factor which highly promoted the healing performance of modified clearcoats. Lower $T_{\mathrm{g}}$ of modified clearcoats compared to blank one was also an outstanding factor which increased the flexibility of the coating and eased the polymeric chain motions during thermal healing process. These changes in the nature of the modified clearcoats network can account for their outstanding healing performance.

\section{Conclusions}

$\mathrm{OH}$-functional HBP and POSS were employed to improve the scratch resistance and healing properties of automotive clearcoats. It was found that self-healing scratch resistant clearcoats can be obtained via controlling the chemical and physical interactions in the coating network composed of various loadings of modifiers. HBP and POSS incorporation into acrylic melamine enhances the elastic recovery of the coating by which the scratch resistance increases. The highly improved healing ability of modified clearcoats was assigned to the change in nature of clearcoat from a more chemical cross-linked structure to a physically cross-linked network in presence of modifiers. Superior healing ability of modified clearcoats was assigned to the reduced functional reactivity, increased polarity and more globularity of HBP and POSS nano-structures.

\section{References}

1 H. Yari, S. Moradian and N. Tahmasebi, J. Coat. Technol. Res., 2013, 11, 351-360.

2 B. Ramezanzadeh, S. Moradian, A. Khosravi and N. Tahmasebi, Prog. Org. Coat., 2011, 72, 541-552.

3 H. Yari, S. Moradian, B. Ramazanzade, A. Kashani and N. Tahmasebi, Polym. Degrad. Stab., 2009, 94, 1281-1289.

4 M. Sangermano and M. Messori, Macromol. Mater. Eng., 2010, 295, 603-612.

5 E. Barna, B. Bommer, J. Kürsteiner, A. Vital, O. v. Trzebiatowski, W. Koch, B. Schmid and T. Graule, Composites, Part A, 2005, 36, 473-480.

6 C. Xiang, H.-J. Sue, J. Chu and B. Coleman, J. Polym. Sci., Part B: Polym. Phys., 2001, 39, 47-59.

7 S. J. Garcia, Eur. Polym. J., 2014, 53, 118-125.

8 S. R. White, N. R. Sottos, P. H. Geubelle, J. S. Moore, M. R. Kessler, S. R. Sriram, E. N. Brown and S. Viswanathan, Nature, 2001, 409, 794-797.
9 S. H. Cho, S. R. White and P. V. Braun, Adv. Mater., 2009, 21, 645-649.

10 S. Bode, L. Zedler, F. H. Schacher, B. Dietzek, M. Schmitt, J. Popp, M. D. Hager and U. S. Schubert, Adv. Mater., 2013, 25, 1634-1638.

11 S. J. García, H. R. Fischer and S. van der Zwaag, Prog. Org. Coat., 2011, 72, 211-221.

12 V. Jardret and P. Morel, Prog. Org. Coat., 2003, 48, 322-331.

13 M. Sadati, N. Mohammadi, N. Taheri Qazvini, N. Tahmasebi and S. Koopahi, Prog. Org. Coat., 2005, 53, 23-28.

14 B. Ramezanzadeh, S. Moradian, A. Khosravi and N. Tahmassebi, J. Coat. Technol. Res., 2010, 9, 203-214.

15 H. Yari, M. Mohseni, Z. Ranjbar, M. Messori and M. R. Naimi-Jamal, Polym. Adv. Technol., 2013, 24, 495-502.

16 N. Bai, G. P. Simon and K. Saito, $R S C A d v .$, 2013, 3, 2069920707.

17 A. Lutz, O. van den Berg, J. Van Damme, K. Verheyen, E. Bauters, I. De Graeve, F. E. Du Prez and H. Terryn, ACS Appl. Mater. Interfaces, 2015, 7, 175-183.

18 S. Bode, M. Enke, R. K. Bose, F. H. Schacher, S. J. Garcia, S. van der Zwaag, M. D. Hager and U. S. Schubert, J. Mater. Chem. A, 2015, 3, 22145-22153.

19 W. Wang, L. Xu, X. Li, Z. Lin, Y. Yang and E. An, J. Mater. Chem. A, 2014, 2, 1914-1921.

20 Q. Zheng, Z. Ma and S. Gong, J. Mater. Chem. A, 2016, 4, 3324-3334.

21 M. M. Caruso, D. A. Delafuente, V. Ho, N. R. Sottos, J. S. Moore and S. R. White, Macromolecules, 2007, 40, 8830-8832.

22 M. L. Szalai, D. V. McGrath, D. R. Wheeler, T. Zifer and J. R. McElhanon, Macromolecules, 2007, 40, 818-823.

23 Y. Zhang, A. A. Broekhuis and F. Picchioni, Macromolecules, 2009, 42, 1906-1912.

24 M. Sangermano, M. Messori, M. M. Galleco, G. Rizza and B. Voit, Polymer, 2009, 50, 5647-5652.

25 H. Yari, S. Moradian, N. Tahmasebi and M. Arefmanesh, Tribol. Lett., 2012, 46, 123-130.

26 B. X. Fu, B. S. Hsiao, H. White, M. Rafailovich, P. T. Mather, H. G. Jeon, S. Phillips, J. Lichtenhan and J. Schwab, Polym. Int., 2000, 49, 437-440.

27 L. Matějka, I. Amici Kroutilová, J. D. Lichtenhan and T. S. Haddad, Eur. Polym. J., 2014, 52, 117-126.

28 E. H. Kim, S. W. Myoung, Y. G. Jung and U. Paik, Prog. Org. Coat., 2009, 64, 205-209.

29 A. Dimopoulos, J.-L. Wietor, M. Wübbenhorst, S. Napolitano, R. A. T. M. van Benthem, G. de With and R. P. Sijbesma, Macromolecules, 2010, 43, 8664-8669.

30 H. Yari, M. Mohseni, M. Messori and Z. Ranjbar, Eur. Polym. J., 2014, 60, 79-91.

31 H. Yari, M. Mohseni and M. Messori, Polymer, 2015, 63, 1929.

32 L. R. Hart, J. H. Hunter, N. A. Nguyen, J. L. Harries, B. W. Greenland, M. E. Mackay, H. M. Colquhoun and W. Hayes, Polym. Chem., 2014, 5, 3680-3688.

33 J. Fox, J. J. Wie, B. W. Greenland, S. Burattini, W. Hayes, H. M. Colquhoun, M. E. Mackay and S. J. Rowan, J. Am. Chem. Soc., 2012, 134, 5362-5368. 
34 S. Burattini, H. M. Colquhoun, J. D. Fox, D. Friedmann, B. W. Greenland, P. J. F. Harris, W. Hayes, M. E. Mackay and S. J. Rowan, Chem. Commun., 2009, 6717-6719.

35 S.-P. Zhao, L.-M. Zhang, D. Ma, C. Yang and L. Yan, J. Phys. Chem. B, 2006, 110, 16503-16507.

36 L. Ruiz-Pérez, G. J. Royston, J. P. A. Fairclough and A. J. Ryan, Polymer, 2008, 49, 4475-4488.

37 M. Ikeda and H. Saito, React. Funct. Polym., 2007, 67, 11481156.

38 T. Liu, Y. Nie, L. Zhang, R. Chen, Y. Meng and X. Li, RSC Adv., 2015, 5, 3408-3416.

39 D. B. Cordes, P. D. Lickiss and F. Rataboul, Chem. Rev., 2010, 110, 2081-2173.

40 C. R. Yates and W. Hayes, Eur. Polym. J., 2004, 40, 1257-1281.

41 N. Tahmassebi and S. Moradian, Polym. Degrad. Stab., 2004, 83, 405-410.

42 B. Ramezanzadeh, M. Mohseni and H. Yari, Prog. Org. Coat., 2011, 71, 19-31.

43 H. Yari, S. Moradian, N. Tahmasebi and M. Arefmanesh, Tribol. Lett., 2012, 46, 123-130.

44 Y. Hara, T. Mori and T. Fujitani, Prog. Org. Coat., 2000, 40, 39-47.

45 E. Amerio, M. Sangermano, G. Colucci, G. Malucelli, M. Messori, R. Taurino and P. Fabbri, Macromol. Mater. Eng., 2008, 293, 700-707.
46 Y. S. Lai, C. W. Tsai, H. W. Yang, G. P. Wang and K. H. Wu, Mater. Chem. Phys., 2009, 117, 91-98.

47 H. Guo, B. N. Nguyen, L. S. McCorkle, B. Shonkwiler and M. A. B. Meador, J. Mater. Chem., 2009, 19, 9054.

48 K. Xie, Y. Wang and L. Xu, Carbohydr. Polym., 2010, 80, 480484.

49 Q. Wei, C. Schlaich, S. Prévost, A. Schulz, C. Böttcher, M. Gradzielski, Z. Qi, R. Haag and C. A. Schalley, Adv. Mater., 2014, 26, 7358-7364.

50 C. Wang, N. Liu, R. Allen, J. B.-H. Tok, Y. Wu, F. Zhang, Y. Chen and Z. Bao, Adv. Mater., 2013, 25, 5785-5790.

51 R. F. M. Lange and E. W. Meijer, Macromol. Symp., 1996, 102, 301-308.

52 G. J. Perpétuo and J. Janczak, J. Mol. Struct., 2008, 891, 429436.

53 T. Seki, S. Yagai, T. Karatsu and A. Kitamura, J. Org. Chem., 2008, 73, 3328-3335.

$54 \mathrm{~J} . \mathrm{Wu}$, T. S. Haddad, G.-M. Kim and P. T. Mather, Macromolecules, 2007, 40, 544-554.

55 N. T. Dintcheva, E. Morici, R. Arrigo, F. P. La Mantia, V. Malatesta and J. J. Schwab, Express Polym. Lett., 2012, 6, 561-571.

56 J. Wu, T. S. Haddad and P. T. Mather, Macromolecules, 2009, 42, 1142-1152. 